\title{
Swimming Through the Gut: Implications of Fluid Transport on the Microbiome
}

\author{
Sean P. Colgan
}

Published online: 30 January 2013

(c) Springer Science+Business Media New York 2013

A primary physiologic function of mucosal epithelial cells is electrolyte transport. In tissues lined by epithelia, such as the lung and intestine, electrolyte transport is accomplished by active ion transport coordinated through a series of membrane transporters [1]. In $\mathrm{Cl}^{-}$secreting epithelium, for instance, the rate-limiting step is entry of $\mathrm{Cl}^{-}$via the $\mathrm{Na}-\mathrm{K}-2 \mathrm{Cl}^{-}$cotransporters [2], a family of proteins that mediate electroneutral transport of $\mathrm{Na}^{+}, \mathrm{K}^{+}$and $\mathrm{Cl}^{-}$ions across cellular membranes [1]. Exit of $\mathrm{Cl}^{-}$across the apical membrane is accomplished by stimulation-dependent transport through chloride channels, the most prevalent of which is the cystic fibrosis transmembrane regulator (CFTR). Mutations in CFTR are associated with the clinical disease cystic fibrosis (CF) through presumed dehydration of mucosal surfaces [3].

Innate immunity in the intestine includes a combination of chemical, mechanical and environmental barriers to the invasion of luminal microbes [4-6]. Water transport and mucosal hydration function are thought to be necessary components of a normally protective barrier based on indirect data gathered from pathologic changes accruing from decreased or increased hydration (e.g., cystic fibrosis or cholera and enterotoxigenic Escherichia coli) [7, 8] and from observations of microbial evasion of normal mucosal clearance mechanisms $[8,9]$. From this perspective, surprisingly little is known about the direct influence of water transport on bacterial-epithelial interactions.

The study by Musch et al. in this issue [10] addresses this issue head-on. They proposed that activation of electrogenic $\mathrm{Cl}^{-}$secretion in the intestinal mucosa alters

S. P. Colgan $(\bowtie)$

University of Colorado School of Medicine, 12700 E 19th Ave, RC2 10025, Mailstop B146, Aurora, CO 80045, USA

e-mail: Sean.Colgan@ucdenver.edu mucus makeup and the composition of the intestinal microbiome. The authors reported that lubiprostone, an agent used clinically in the treatment of constipation [10], stimulates electrogenic $\mathrm{Cl}^{-}$secretion, and presumably water transport, in the jejunum, ileum and throughout the colon. Somewhat surprisingly, lubiprostone decreased the thickness of the inner mucus layer of the colon and fundamentally shifted the composition of stool microbiome. These studies provide immediate confirmation of our own work, where we recently reported that active electrogenic $\mathrm{Cl}^{-}$secretion (elicited by lubiprostone) functions as a primitive innate defense mechanism, substantially shifting the colonic microbiota with notable changes in both Firmicutes and Bacteroidetes phyla of resident colonic bacteria [11]. In particular, the work by Musch et al. [10] and our own studies [11] reveal, among others, the increased association of Lactobacillus spp. in stool samples of lubiprostone-treated mice, which likely reflect a more "protective" microbiome. Indeed, the beneficial influences of lactobacilli are exemplified by their common use as probiotic agents $[12,13]$. Lactobacillus spp. possess antiinflammatory properties in addition to other host beneficial influences including colonization resistance, increased availability of nutrients to the intestine, and improved digestion [13]. The anti-inflammatory activity of colonic lactobacilli is attributable to cell surface proteins interacting with the host immune response [14]. In IL-10 ${ }^{-/-}$ spontaneous colitis mouse models, abnormal colonization of lactobacilli was present that when normalized, reduced levels of mucosal adherent bacteria and attenuated the development of colitis [15]. Of interest for the present work, colons from IL-10 $0^{-/-}$mice have significant defects in activated $\mathrm{Cl}^{-}$secretion, linked to decreased expression of the CFTR [16]. It is possible, therefore, that water transport, and associated changes to the mucus gel layer, 
promotes the colonization of lactobacilli, promoting colonic homeostasis.

Of particular relevance to the work by Musch et al. [10] is the possibility that lubiprostone could benefit patients with intestinal manifestations of CF. Intestinal symptoms are a common and debilitating complication of CF resulting from thickened mucus, perpetuating inflammation [17]. While this topic is controversial [18], the present work and work by others [19] have reported that the $\mathrm{Cl}^{-}$secretory activity of lubiprostone largely bypasses the CFTR and, thus, lubiprostone may provide an alternative mechanism for mucosal hydration in these patients. Likewise, there is currently intense interest in elucidating the composition of the microbial communities in CF. In mouse models, significant shifts in the intestinal microbiota correlate with the most common clinical CF-associated mutations [20]. Whether treatment of patients with lubiprostone could influence the microbiome and overall intestinal health of such patients is anxiously anticipated by many.

\section{References}

1. Gamba G. Molecular physiology and pathophysiology of electroneutral cation-chloride cotransporters. Physiol Rev. 2005;85:423-493.

2. Barrett KE, Keely SJ. Chloride secretion by the intestinal epithelium: molecular basis and regulatory aspects. Annu Rev Physiol. 2000;62:535-572.

3. Rowe SM, Miller S, Sorscher EJ. Cystic fibrosis. $N$ Engl J Med. 2005;352:1992-2001.

4. Campbell EL, Serhan CN, Colgan SP. Antimicrobial aspects of inflammatory resolution in the mucosa: a role for proresolving mediators. J Immunol. 2011;187:3475-3481.

5. IvanovAI, Parkos CA, Nusrat A. Cytoskeletal regulation of epithelial barrier function during inflammation. Am J Pathol. 2010; 177:512-524.

6. Turner JR. Intestinal mucosal barrier function in health and disease. Nat Rev Immunol. 2009;9:799-809.
7. Clunes MT, Boucher RC. Introduction to section I: overview of approaches to study cystic fibrosis pathophysiology. Methods Mol Biol. 2010;742:3-14.

8. Glenn GM, Francis DH, Danielsen EM. Toxin-mediated effects on the innate mucosal defenses: implications for enteric vaccines. Infect Immun. 2009;77:5206-5215.

9. Hallstrom K, McCormick BA. Salmonella Interaction with and passage through the Intestinal Mucosa: through the lens of the organism. Front Microbiol. 2011;2:88.

10. Musch MW, Young W, Claud EC, Chang EB. Lubiprostone decreases mouse colonic inner mucus layer thickness and alters intestinal microbiota. Dig Dis Sci. 2012. (Epub ahead of print). doi:10.1007/s10620-012-2509-5.

11. Keely S, Kelly C, Weissmueller T, et al. Activated fluid transport regulates bacterial-epithelial interactions and significantly shifts the murine colonic microbiome. Gut Microbes. 2012;3:250-260.

12. Boesten RJ, de Vos WM. Interactomics in the human intestine: lactobacilli and Bifidobacteria make a difference. J Clin Gastroenterol. 2008;42:S163-S167.

13. Reading NC, Kasper DL. The starting lineup: key microbial players in intestinal immunity and homeostasis. Front Microbiol. 2011;2:1-10.

14. Sanchez B, Urdaci MC, Margolles A. Extracellular proteins secreted by probiotic bacteria as mediators of effects that promote mucosabacteria interactions. Microbiology. 2010;156:3232-3242.

15. Madsen KL, Doyle JS, Jewell LD, Tavernini MM, Fedorak RN. Lactobacillus species prevents colitis in interleukin 10 genedeficient mice. Gastroenterology. 1999;116:1107-1114.

16. Walker J, Jijon HB, Churchill T, Kulka M, Madsen KL. Activation of AMP-activated protein kinase reduces cAMP-mediated epithelial chloride secretion. Am J Physiol Gastrointest Liver Physiol. 2003;285:G850-G860.

17. Colombo C, Ellemunter H, Houwen R, Munck A, Taylor C, Wilschanski M. Guidelines for the diagnosis and management of distal intestinal obstruction syndrome in cystic fibrosis patients. J Cyst Fibros. 2011;10:S24-S28. doi:10.1016/S1569-1993(1011)60005-60002.

18. Bijvelds MJ, Bot AG, Escher JC, De Jonge HR. Activation of intestinal Cl- secretion by lubiprostone requires the cystic fibrosis transmembrane conductance regulator. Gastroenterology. 2009;137:976-985.

19. De Lisle RC, Mueller R, Roach E. Lubiprostone ameliorates the cystic fibrosis mouse intestinal phenotype. BMC Gastroenterol. 2010;10:107.

20. Lynch SV, Goldfarb KC, Wild Y, Kong W, De Lisle RC, Brodie EL. Cystic fibrosis transmembrane conductance regulator knockout mice exhibit aberrant gastrointestinal microbiota. Gut Microbes. 2012;4:1. 